\title{
OPTIMIZATION OF MICROWAVE HYDRODISTILLATION OF DRIED PATCHOULI LEAVES BY RESPONSE SURFACE METHODOLOGY
}

\author{
H. S. Kusuma*, M.E. Syahputra, D. Parasandi, A. Altway and M. Mahfud* \\ Department of Chemical Engineering, Faculty of Industrial Engineering, Institut Teknologi \\ Sepuluh Nopember, 60111, Indonesia \\ *E-mail: heriseptyakusuma@gmail.com; mahfud@chem-eng.its.ac.id
}

\begin{abstract}
This paper deals with the optimization of patchouli oil yield in microwave hydrodistillation using response surface methodology (RSM). The factors considered were microwave power (A), feed to the solvent ratio (B) and extraction time (C). These parameters were varied at two levels. The conditions of optimum patchouli oil yield predicted were microwave power of $467.517 \mathrm{~W}$, feed to solvent ratio of $0.432 \mathrm{~g} / \mathrm{mL}$ and extraction time of $152.122 \mathrm{~min}$. These factors gave an optimum patchouli oil yield of $4.862 \%$. The significant model terms are extraction time. Analysis of variance (ANOVA) indicates that the model was significant as evidenced from $\mathrm{R}^{2}$ of 0.9036 and the model F-value of 7.29. The patchouli oil yield predicted by the model was closed to the experimentally determined values $(1.85 \%$ and 1.87 $\%$ respectively); hence the model can be used for prediction of patchouli oil yield in essential oil extraction from dried patchouli leaves using microwave hydrodistillation method.
\end{abstract}

Keywords: Box-Behnken design; microwave hydrodistillation; patchouli oil.

(C) RASĀYAN. All rights reserved

\section{INTRODUCTION}

Patchouli is one of the essential oil producing plants which is quite important as Indonesia's export commodity and contributes about $60 \%$ of the total export of Indonesian essential oil. Indonesia is the world's largest supplier of patchouli oil with the contribution of $90 \%{ }^{1}$. Currently, the extraction of patchouli oil is still done using conventional methods that generally have a smaller yield, takes relatively long time and requires a large cost. This is supported by research data that the extraction of basil oil using hydrodistillation method with feed to solvent ratio of $0.5 \mathrm{~g} / \mathrm{mL}$ for 1 hour obtained yield as much as $0.95 \pm 0.08 \%(\mathrm{v} / \mathrm{w})^{2}$.

Therefore, consideration should be given to using a new "green technique" in the extraction of essential oils with minimum energy, solvent, and time usage. Until now it has developed new methods to extract essential oils, one of which is using the microwave (microwave-assisted extraction).

Previous research has shown that the extraction using the microwave is an alternative that could be developed than the conventional methods, because of the high levels of product purity, lack of solvent usage, and processing time is short ${ }^{3}$. Some extraction using the microwave that has been successfully developed is microwave hydrodistillation method which is a combination of hydrodistillation with microwave heating ${ }^{4}$.

This is supported by previous studies that had been conducted by Asghari et al. ${ }^{5}$ which showed that the extraction of essential oil from Ferulago angulata using microwave hydrodistillation method is more effective and efficient when compared with hydrodistillation method. Based on these research, the extraction of essential oil from Ferulago angulata using microwave hydrodistillation method with feed to solvent ratio of $0.067 \mathrm{~g} / \mathrm{mL}$ and microwave power of $650 \mathrm{~W}$ for 70 minutes obtained a yield of $3.8 \%$. While for the extraction of essential oil from Ferulago angulata using hydrodistillation method with feed to solvent ratio of $0.083 \mathrm{~g} / \mathrm{mL}$ for 3 hours obtained a yield of $1.7 \% 5$. Therefore, in this study conducted extraction of patchouli oil using microwave hydrodistillation method. 
In the extraction of patchouli oil using microwave hydrodistillation, the extraction parameters need to be optimized. Response Surface Methodology (RSM) is a collection of mathematical and statistical techniques useful for modeling and analyzing of problems in which a response of interest is influenced by some quantitative variables with the objective of optimizing the response ${ }^{6}$. In this study, an attempt was made at optimizing microwave hydrodistillation of patchouli oil using response surface methodology.

\section{Material and Chemicals}

\section{EXPERIMENTAL}

The dried patchouli leaves used in this study were obtained from Trenggalek, East Java, Indonesia and have a size of $2.45 \pm 0.56 \mathrm{~cm}$. The distilled water and anhydrous sodium sulfate used in the study were of analytical grade.

\section{Microwave Hydrodistillation Method}

In employing microwave hydrodistillation, we used a domestic microwave oven (EMM2308X, Electrolux, maximum delivered power of $800 \mathrm{~W}$ ) with a wave frequency of $2450 \mathrm{MHz}$. The dimensions of the PTFEcoated cavity of the microwave oven were $48.5 \mathrm{~cm}$ x $37.0 \mathrm{~cm}$ x $29.25 \mathrm{~cm}$. The microwave oven was modified by drilling a hole at the top. A round bottom flask with a capacity of $1000 \mathrm{ml}$ was placed inside the oven and was connected to the three-way adapter and liebig condenser through the hole. Then, the hole was closed with PTFE to prevent any loss of the heat inside.

Some feed to solvent ratio $(0.3 ; 0.4 ; 0.5 \mathrm{~g} / \mathrm{mL})$ were placed in the reaction flask and heated by microwave irradiation with various power $(300 ; 450 ; 600 \mathrm{~W})$ and various extraction time $(60 ; 120 ; 180 \mathrm{~min})$. The different densities and their immiscibility required that the water and patchouli oil be separated from each other by separating funnel and the excess water be refluxed to the extraction vessel in order to provide uniform conditions of solid-to-liquid ratios for extraction. The patchouli oil was collected in amber vials, dried under anhydrous sodium sulfate and stored at $4^{\circ} \mathrm{C}$. The extraction yield of patchouli oil was calculated according to the equation given:

Extraction yield $(\%, w / w)=\frac{\text { Mass of extracted patchouli oil }}{\text { Mass of dried patchouli leaves } \mathrm{x}(1-\text { water content })} \times 100$

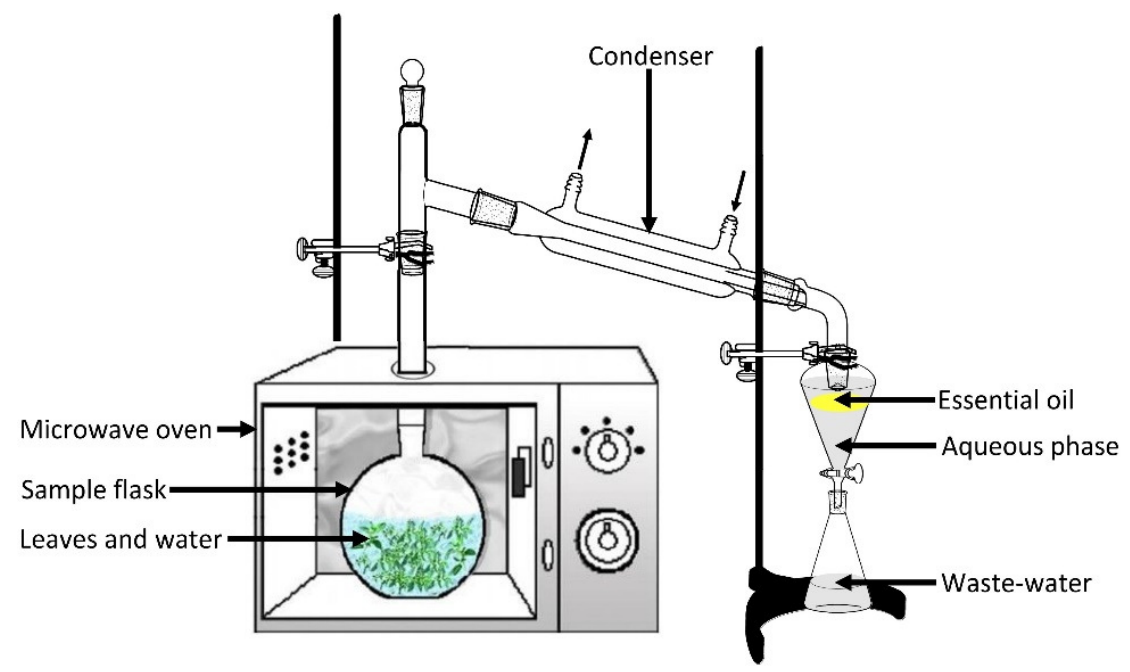

Fig.-1: Schematic representation of the microwave hydrodistillation apparatus used in this study

\section{Design of Experiment}

A $2^{3}$ Box-Behnken Design (BBD) was employed resulting in a total of 17 experiments using the DesignExpert version 9.0.4.1 (State-Ease Inc., Minneapolis, MN, USA) to optimize the chosen key factors namely microwave power (A), feed to the solvent ratio (B) and extraction time (C). These variables each at two levels, low and high: A $(300-600 \mathrm{~W}), \mathrm{B}(0.3-0.5 \mathrm{~g} / \mathrm{mL})$ and $\mathrm{C}(60-180 \mathrm{~min})$ are presented in Table-1. 
These levels were chosen based on the capacity of the experimental set up for variables A and B, while C was selected based on experimental run time. The experimental design is shown in Table-2.

Table-1: Design summary

\begin{tabular}{c|l|c|c|c|c|c}
\hline Factors & \multicolumn{1}{|c|}{ Name } & Units & Low Actual & High Actual & Low Coded & High Coded \\
\hline $\mathrm{A}$ & Microwave power & $\mathrm{W}$ & 300 & 600 & -1 & 1 \\
\hline $\mathrm{B}$ & Feed to solvent ratio & $\mathrm{g} / \mathrm{mL}$ & 0.3 & 0.5 & -1 & 1 \\
\hline $\mathrm{C}$ & Extraction time & $\mathrm{min}$ & 60 & 180 & -1 & 1 \\
\hline
\end{tabular}

The regression analysis was performed to estimate the response function as a second order polynomial $Y=\beta_{0}+\sum_{i=1}^{k} \beta_{i i} X_{i}^{2}+\sum_{i=1}^{k-1} \sum_{j=2}^{k} \beta_{i j} X_{i} X_{j}$

where $Y$ is the predicted response, $X_{i}$ is the uncoded value of the $i$-th test variable, $\beta_{0}, \beta_{j}$ and $\beta_{i j}$ are coefficients estimated from the regression according to Rajasimman et al. ${ }^{7}$

A statistical program package Design-Expert version 9.0.4.1 (State-Ease Inc., Minneapolis, MN, USA) was used for regression analysis of the data and for estimating the coefficient of the regression equation. The equations were validated by the analysis of variance (ANOVA) test. Model and regression coefficients were considered significant when the $\mathrm{p}$-value was lower than $0.05^{8}$.

Table-2: Box-Behnken Design matrix

\begin{tabular}{c|c|c|c|c|c|c}
\hline \multirow{2}{*}{ Run } & \multicolumn{3}{|c|}{ Actual variables } & \multicolumn{3}{c}{ Yield (\%) } \\
\cline { 2 - 7 } & $\mathrm{A}(\mathrm{W})$ & $\mathrm{B}(\mathrm{g} / \mathrm{mL})$ & $\mathrm{C}(\min )$ & Experimental & Predicted & Residue \\
\hline 1 & 300 & 0.3 & 120 & 3.0221 & 2.7454 & 0.2767 \\
\hline 2 & 300 & 0.4 & 60 & 2.3617 & 2.2383 & 0.1234 \\
\hline 3 & 300 & 0.4 & 180 & 3.7482 & 3.7070 & 0.0412 \\
\hline 4 & 300 & 0.5 & 120 & 2.7831 & 3.2250 & -0.4419 \\
\hline 5 & 450 & 0.3 & 60 & 2.4343 & 2.8349 & -0.4006 \\
\hline 6 & 450 & 0.3 & 180 & 3.3429 & 3.6613 & -0.3185 \\
\hline 7 & 450 & 0.4 & 120 & 4.6493 & 4.6495 & -0.0002 \\
\hline 8 & 450 & 0.4 & 120 & 4.6493 & 4.6495 & -0.0002 \\
\hline 9 & 450 & 0.4 & 120 & 4.6493 & 4.6495 & -0.0002 \\
\hline 10 & 450 & 0.4 & 120 & 4.6493 & 4.6495 & -0.0002 \\
\hline 11 & 450 & 0.4 & 120 & 4.6493 & 4.6495 & -0.0002 \\
\hline 12 & 450 & 0.5 & 60 & 3.3471 & 3.0291 & 0.3180 \\
\hline 13 & 450 & 0.5 & 180 & 4.9240 & 4.5239 & 0.4001 \\
\hline 14 & 600 & 0.3 & 120 & 3.6771 & 3.2356 & 0.4415 \\
\hline 15 & 600 & 0.4 & 60 & 3.0438 & 3.0855 & -0.0416 \\
\hline 16 & 600 & 0.4 & 180 & 3.8141 & 3.9379 & -0.1238 \\
\hline 17 & 600 & 0.5 & 120 & 3.5357 & 3.8128 & -0.2771 \\
\hline
\end{tabular}

\section{RESULTS AND DISCUSSION}

Table-2 presents the Box-Behnken Design matrix and the patchouli oil yield obtained for each experimental run. Analysis of variance for the response surface model is presented in Table-3. The analysis indicates that the model F-value of 7.29 implies the model is significant. There is only a $0.79 \%$ chance that an F-value this large could occur due to noise, the model also has a satisfactory level of adequacy $\left(\mathrm{R}^{2}\right)$. In this study $\mathrm{C}, \mathrm{A}^{2}, \mathrm{~B}^{2}$ and $\mathrm{C}^{2}$ are significant model terms $(\mathrm{p}<0.05)$.

Table-3: Analysis of variance (ANOVA) for response surface quadratic model to identify significant factors affecting the patchouli oil yield

\begin{tabular}{c|c|c|c|c|c}
\hline Source & Sum of Squares & df & Mean Square & F Value & p-Value \\
\hline Model & 10.31 & 9 & 1.15 & 7.29 & $0.0079^{*}$ \\
\hline A & 0.58 & 1 & 0.58 & 3.69 & 0.0960 \\
\hline B & 0.56 & 1 & 0.56 & 3.55 & 0.1015 \\
\hline
\end{tabular}


RASĀYAN J. Chem.

Vol. 10 | No. 3 |861 - 865 | July - September | 2017

\begin{tabular}{c|c|c|c|c|c}
\hline $\mathrm{C}$ & 2.69 & 1 & 2.69 & 17.13 & $0.0044^{*}$ \\
\hline $\mathrm{AB}$ & 0.002385 & 1 & 0.002385 & 0.015 & 0.9054 \\
\hline $\mathrm{AC}$ & 0.095 & 1 & 0.095 & 0.60 & 0.4625 \\
\hline $\mathrm{BC}$ & 0.11 & 1 & 0.11 & 0.71 & 0.4272 \\
\hline $\mathrm{A}^{2}$ & 2.92 & 1 & 2.92 & 18.56 & $0.0035^{*}$ \\
\hline $\mathrm{B}^{2}$ & 1.33 & 1 & 1.33 & 8.47 & $0.0227^{*}$ \\
\hline $\mathrm{C}^{2}$ & 1.39 & 1 & 1.39 & 8.85 & $0.0207^{*}$ \\
\hline Residual & 1.10 & 7 & 0.16 & & \\
\hline Lack of Fit & 1.10 & 3 & 0.37 & & \\
\hline Pure Error & 0.000 & 4 & 0.000 & & \\
\hline Cor Total & 11.41 & 16 & & & \\
\hline
\end{tabular}

Standard deviation: 0.40; $\mathrm{R}^{2}$ : 0.9036; Adj $\mathrm{R}^{2}$ : 0.7796; Pred $\mathrm{R}^{2}$ : -0.5427; Adeq precision: 7.928

*Significant variable

The Pred $\mathrm{R}^{2}$ of -0.5427 implies that the overall mean is a better predictor of the response than the current model. Adeq Precision measures the signal to noise ratio; the ratio of 7.928 obtained indicates an adequate signal (a ratio greater than 4 is desirable). Therefore the model can be used to navigate the design space. The response surface curves are plotted to understand the interaction of the variables and the optimum level of each variable for maximum response ${ }^{7}$. The response surface curves for extraction of patchouli oil using microwave hydrodistillation are presented in Fig.-2. Fig.-2(a) shows the interaction of microwave power and feed to solvent ratio on the yield, while Fig.-2(b) and 2(c) indicates interaction of microwave power and extraction time on the yield as well as that of feed to solvent ratio and extraction time on the yield, respectively. Final equation in terms of actual variables is given by Equation-3.

$$
\begin{aligned}
\text { Yield }= & -16.46046+0.036499 A+43.55528 B+0.044561 C \\
& +1.62794 .10^{-3} A B-1.71199 .10^{-5} A C+0.027848 B C \\
& -3.69989 .10^{-5} A^{2}-56.23451 B^{2}-1.59685 .10^{-4} C^{2}
\end{aligned}
$$

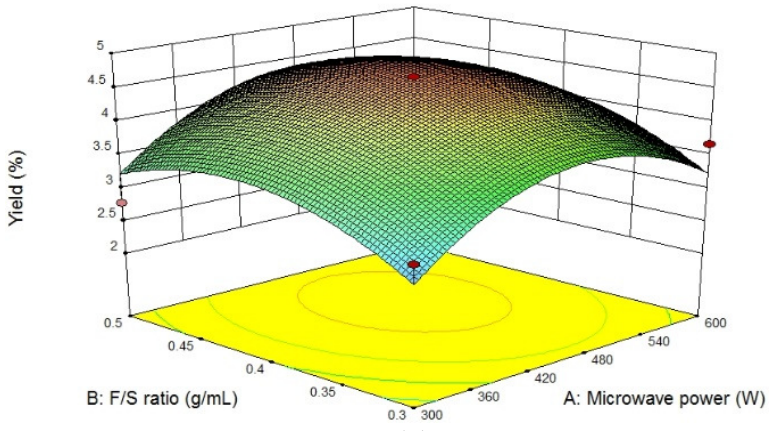

(a)

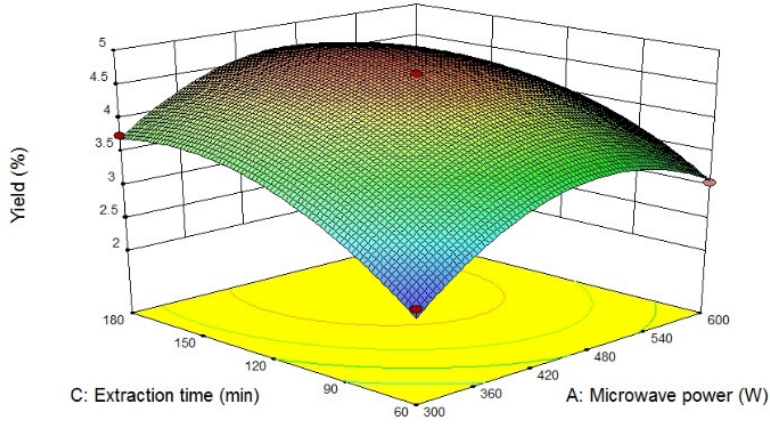

(b)

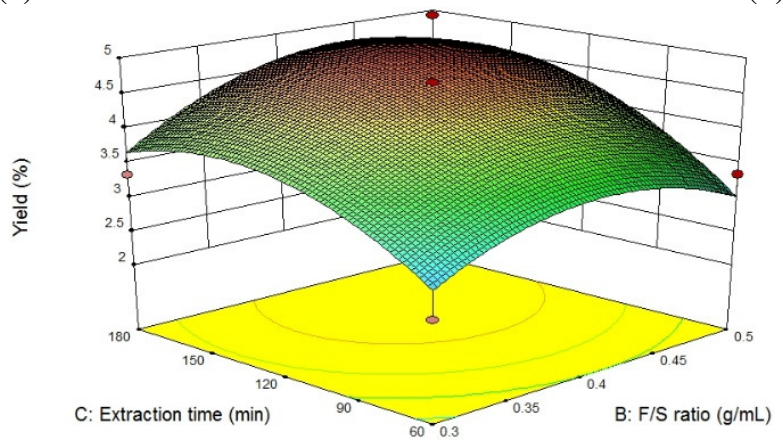

(c)

Fig.-2: Response surface showing effect of (a) microwave power and feed to solvent (F/S) ratio on the yield at constant extraction time (120 min); (b) microwave power and extraction time on the yield at constant feed to solvent $(\mathrm{F} / \mathrm{S})$ ratio $(0.4 \mathrm{~g} / \mathrm{mL})$; (c) feed to solvent $(\mathrm{F} / \mathrm{S})$ ratio and extraction time on the yield at constant microwave power $(450 \mathrm{~W})$ 
Experimental data generated in Table- 2 in terms of actual values were substituted into Equation-3 and the predicted patchouli oil yield was obtained. Actual patchouli oil yield and the predicted patchouli oil yield are presented in Table-2; Comparison of these values indicates that the 2 sets of values are in close agreement. This suggests good reliability of the model as also evidenced from the statistical parameters of the model such as standard deviation of $0.40, \mathrm{R}^{2}$ of 0.9036 and F-value of 7.29. This shows fitness of the data for the model.

Numerical optimization method was used to predict optimum condition for the response using the DesignExpert version 9.0.4.1 (State-Ease Inc., Minneapolis, MN, USA). The microwave power of 467.517 W, feed to solvent ratio of $0.432 \mathrm{~g} / \mathrm{mL}$ and extraction time of 152.122 min were obtained among the solutions for the optimum conditions for the yield. This condition gives a yield of $4.862 \%$.

\section{CONCLUSION}

The optimization model was developed using response surface methodology technique for prediction of patchouli oil yield in microwave hydrodistillation of dried patchouli leaves. The model fits experimental data. The extraction time is the major process parameters found to significantly influence the patchouli oil yield. The conditions of optimum patchouli oil yield predicted were microwave power of $467.517 \mathrm{~W}$, feed to solvent ratio of $0.432 \mathrm{~g} / \mathrm{mL}$ and extraction time of $152.122 \mathrm{~min}$, which gives patchouli oil yield of $4.862 \%$.

\section{REFERENCES}

1. H.S. Kusuma and M. Mahfud, RSC Advances, 7, 1336(2017a).

2. D.J. Charles and J.E. Simon, Journal of the American Society for Horticultural Science, 115(3), 458(1990).

3. H.S. Kusuma and M. Mahfud, Periodica Polytechnica Chemical Engineering, 61(2), 82 (2017b).

4. H.S. Kusuma and M. Mahfud, Journal of Applied Research on Medicinal and Aromatic Plants, 4, 55(2017c).

5. J. Asghari, C.K. Touli, M. Mazaheritehrani and M. Aghdasi, European Journal of Medicinal Plants, 2(4), 324(2012).

6. R.H. Myers and R.C. Montgomery, Response Surface Methodology, Process and Product Optimization using Design Experiment, Wiley, New York (2002).

7. M. Rajasimman, R. Sangeetha and P. Karthik, Chemical Engineering Journal, 150, 275 (2009).

8. S. Liu, F. Yang, C. Zhang, H. Ji, P. Hong and C. Deng, The Journal of Supercritical Fluids, 48, 9(2009).

[RJC-1763/2017] 